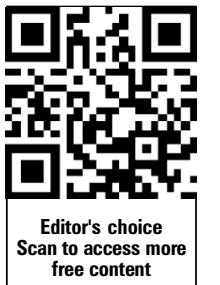

free content

\title{
Dysfunction of the locus coeruleus-norepinephrine system and related circuitry in Parkinson's disease-related dementia
}

\author{
Kelly Del Tredici, Heiko Braak
}

\begin{abstract}
Clinical Neuroanatomy, Center for Biomedical Research, Department of Neurology, University of Ulm, Ulm, Germany
\end{abstract}

\section{Correspondence to}

Professor H Braak, Clinical Neuroanatomy Section, Center for Biomedical Research, Department of Neurology, University of Ulm, Helmholtzstrasse 8/1, Ulm 89081, Germany; heiko.braak@uni-ulm.de

Received 17 June 2012 Revised 29 August 2012 Accepted 3 September 2012 Published Online First 13 October 2012
To cite: Del Tredici K, Braak H. J Neurol Neurosurg Psychiatry 2013;84: 774-783.

\begin{abstract}
Although resting tremor, cogwheel rigidity, hypokinesia/ bradykinesia and postural instability usually dominate the clinical picture of sporadic Parkinson's disease (PD), both clinical and epidemiological data reveal that a wide variety of additional symptoms impair patients' quality of life considerably, parallel to the chronic progressive neurodegenerative movement disorder. Autopsy based retrospective studies have shown that $\alpha$-synuclein immunoreactive Lewy pathology (LP) develops in the locus coeruleus (LC) of patients with neuropathologically confirmed sporadic PD, as well as in individuals with incidental (prodromal or premotor) Lewy body disease but not in age and gender matched controls. Using five case studies, this review discusses the possible role of LP (axonopathy, cellular dysfunction and nerve cell loss) in the $L C$, catecholaminergic tract and related circuitry in the development of PD-related dementia. The contribution of noradrenergic deficit to cognitive dysfunction in PD has been underappreciated. Noradrenergic therapeutic interventions might not only alleviate depressive symptoms and anxiety but also delay the onset of cognitive decline.
\end{abstract}

\section{INTRODUCTION}

In sporadic Parkinson's disease (PD), Lewy pathology (LP) is not only present in the brain but throughout the entire human nervous system. ${ }^{1-8}$ Morphologically, LP consists of insoluble intraneuronal inclusions that contain the misfolded protein $\alpha$-synuclein in aggregated form $^{9-13}$ : immunoreactive pale neurites, thread-like or spindle-shaped Lewy neurites (LNs) in axons and dendrites ${ }^{14} 15$ (figure 1A) as well as particulate (or punctate) aggregates, ${ }^{16}$ pale bodies ${ }^{17}$ and Lewy bodies (LBs) within neuronal cell somata ${ }^{10} 1819$ (figure 1B, C).

LP accompanied by nerve cell loss occurs in the locus coeruleus (LC) of the pontine tegmentum during $\mathrm{PD},{ }^{20-27}$ and there is firm evidence that involvement of this nucleus and other regions in incidental Lewy body disease (ILBD) precedes the appearance of $\alpha$-synuclein aggregates and neuronal loss in the nigral pars compacta. ${ }^{28-33}$ Less attention, however, has been paid to the possible association of LP with noradrenergic axonal or cellular dysfunction there and its potential consequences. Until recently, for instance, diminution of tyrosine hydroxylase $(\mathrm{TH})$ immunoreactivity in PD and ILBD had only been detected in cardiac sympathetic nerves, ${ }^{34} 35$ but several groups have shown that this phenomenon is not restricted to the peripheral nervous system: in an autopsy-based study, ILBD cases were seen to have reduced striatal $\mathrm{TH},{ }^{36}$ and subsequent reports have described abnormalities in TH immunoreactivity within the LC in cases with PD. ${ }^{25}{ }^{37}$ For example, Dugger and Dickson recently found that compared with controls, coeruleus projection neurones of PD patients displayed reduced or depleted cytoplasmic immunoreactivity for $\mathrm{TH}$ (figure 1D) and that the melanised nerve cells there also sequestered TH within abnormal $\alpha$-synuclein aggregates, ${ }^{37}$ thereby making it unavailable for essential brain functions ${ }^{38}$ (figure 1D-F).

The LC is the largest source of noradrenergic innervation in the human brain with ascending projections to all regions of the cerebral cortex (hippocampal formation, entorhinal cortex with adjacent mediotemporal cortex, cingulate gyrus and neocortex). ${ }^{39-41}$ One of the major functions of the LC-norepinephrine system is to maximise task-oriented performance and behaviour, particularly under challenging (novel, stressful) circumstances. $^{42-44}$ In addition, together with the gigantocellular nucleus of the pontine reticular formation and the nuclei of the lower raphé group, the LC receives supramedullary limbic (central subnucleus of the the amygdala) and somatomotor input (pedunculopontine tegmental nucleus $(\mathrm{PPN}))$. Together with the projections from the lower raphé group, projections from the LC have an inhibitory effect on responses to pain in decisive situations and a facilitatory effect on the activity levels of spinal cord premotor and motoneurons that receive data from the neocortex, striatal and cerebellar circuits ${ }^{45-50}$ (figure 2). Finally, the LC participates in the sympathetic innervation and modulation of the brain microcirculation. ${ }^{44} 51-58$ Thus, loss or chronic reduction of the rate limiting enzyme $\mathrm{TH}$ for norepinephrine metabolism within the LC and/or the ascending catecholaminergic tract (equivalent to the rat dorsal noradrenergic ascending bundle $)^{59}$ may be anticipated to contribute not only to some of the motor difficulties experienced by PD patients in 'unexpected' situations (eg, no abrupt turns and hesitation at thresholds) but also to problems with wake-arousal states or redirecting attention, and to deficits in cognitive function and the cerebral microcirculation. ${ }^{38} 58$ 60-62

During PD neuropathological stage 2, the level setting nuclei (ie, LC, gigantocellular reticular nucleus and lower raphe nuclei) as a unit become involved and, during the following stage, a bifurcation, as it were, of the pathological process in the 


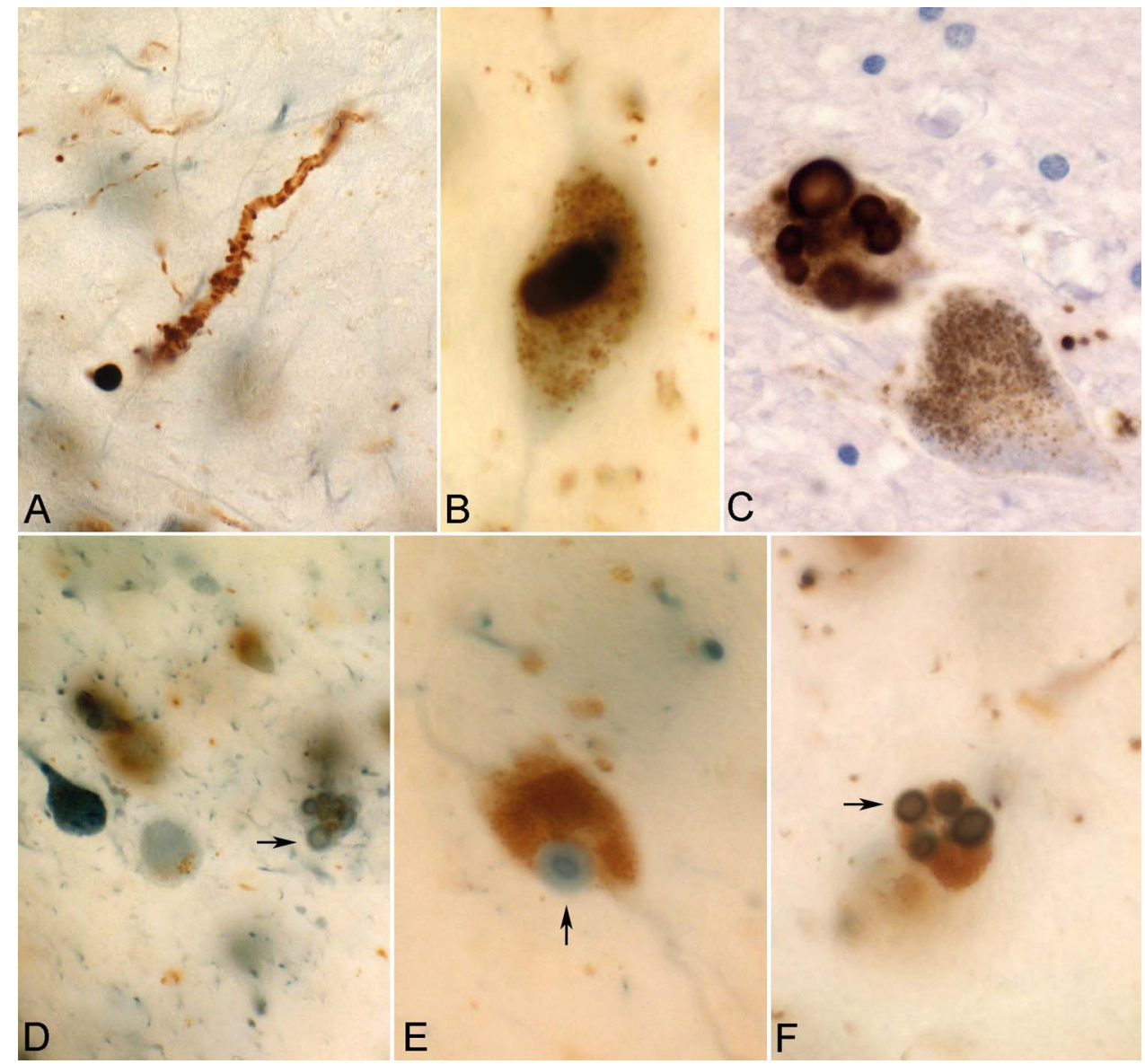

Figure 1 Lewy pathology in brains of demented patients with Parkinson's disease. (A) Micrograph of a Lewy neurite showing immunoreactive material on the inner cellular membrane of a dendrite covered with short appendages. (B-F) Particulate $\alpha$-synuclein aggregates in melanised projection neurones of the locus coeruleus (LC) (B) and substantia nigra (C, lower right). Lewy bodies are also seen ( $B, C)$, whereby in (D-F) (the LC), they clearly sequester tyrosine hydroxylase (TH, arrows) in their halos or centres. As such, the neurotransmitter presumably is not available for brain noradrenergic metabolism. (D) Compare the normal appearing melanised neurone at the left (dark blue, chromogen SK-4700) with that directly to the right: the cytoplasm of the latter nerve cell is pale, indicating reduced TH activity. Immunoreactions for $\alpha$-synuclein (C) and for $\alpha$-synuclein plus TH (A, B, D-F) in polyethylene glycol embedded $100 \mu \mathrm{m}$ sections.

brain occurs: LP develops in high order relay centres of the central autonomic network (central subnucleus of the amygdala, hypothalamus and limbic circuit components) ${ }^{22} 63$ and, at the same time, it progresses into superordinate centres of the somatomotor system, including the PPN nucleus and striatal circuit ${ }^{64-66}$ (figure 2). The central autonomic network and PPN nucleus regulate the brainstem level setting nuclei and send projections to all diffusely projecting non-thalamic nuclei. ${ }^{48}{ }^{67}$ In other words, by the time the PD associated pathological process makes headway into cortical sites during PD neuropathological stage 4, the LP and axonal and/or cellular dysfunction and neuronal loss in key brainstem serotonergic, noradrenergic and cholinergic neurones are fairly advanced $2227376468-70$ (figures 2 and 6).

There is now a consensus that PD patients develop dysexecutive symptoms and, provided they live long enough, dementia. ${ }^{71-77}$ However, the differential diagnosis between PD associated dementia (PDD) and dementia with Lewy bodies (DLB) is still fraught with difficulties. ${ }^{78-80}$ For instance, use of the 1 year rule originally proposed by McKeith et al ${ }^{81}$ - that is, parkinsonism prior to cognitive impairment/fluctuating cognition-to differentiate DLB from PDD clinically is, in our view, unsatisfactory because it is arbitrary and because comorbid pathologies also can contribute to the development of dementia in PD. ${ }^{61}{ }^{82-85}$ In fact, depending on the parameters applied as well as cohort composition and size, the neuropathological substrates of cognitive decline and dementia in PD have been attributed not only to cortical (limbic and neocortical) LP ${ }^{718386-89}$ but also to lesions compatible with Alzheimer's disease (AD) $617282838790-95$ and, somewhat more infrequently, comorbid argyrophilic grain disease (AGD)..$^{83}$ 96-98 Potential mechanisms that might contribute to a synergistic effect between tau and $\alpha$-synuclein or between $\alpha$-synuclein and amyloid- $\beta$ remain the object of ongoing research and discussion. ${ }^{99-106}$ In addition, intracerebral vascular disease, including amyloid angiopathies and subcortical arteriosclerotic encephalopathy (small vessel disease with white matter lesions) are recognised as contributory factors. ${ }^{85} 107108$ Thus the entities cognitive dysfunction and dementia in PD are often associated with an admixture of pathologies-that is, PD plus AD or PD plus AD plus AGD-often accompanied by a vascular component. ${ }^{109}$

Finally, dopamine replacement therapy can have undesirable effects not only on behaviour but also on cognitive function. ${ }^{110-112}$

\section{CASE HISTORIES AND POST MORTEM DIAGNOSES IN FIVE PATIENTS WITH PD AND DEMENTIA}

Each of the autopsied PD cases below fulfilled the criteria for the clinical and neuropathological diagnoses of PD. ${ }^{113}$ One set of tissue blocks used for staging PD related synucleinopathy of the brain, as described earlier, ${ }^{22}$ was dissected from each case, 


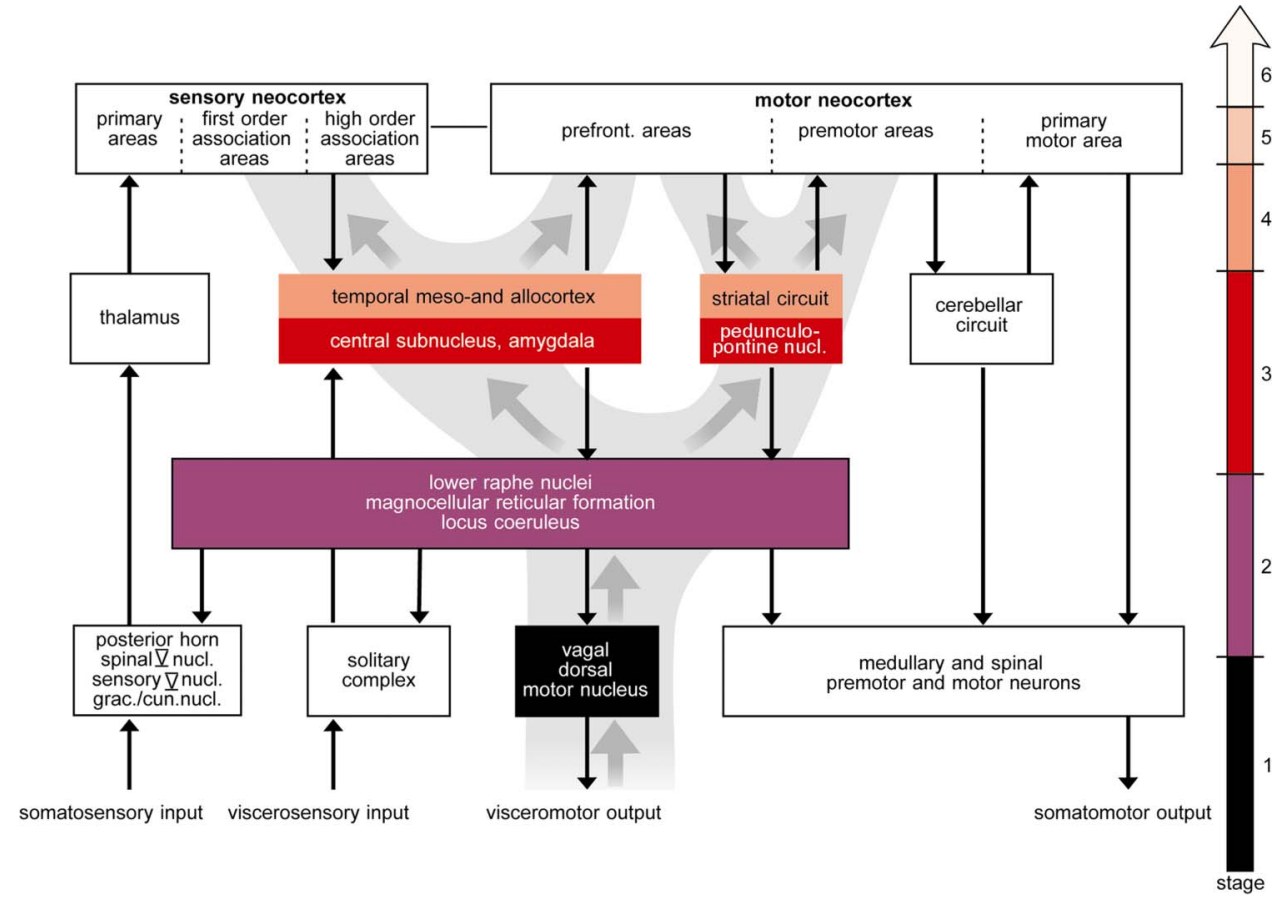

Figure 2 Dendrogram showing six neuropathological stages of Parkinson's disease (PD). Note that by the time the disease process diverges into important limbic system and somatomotor system centres (stage 3), the lower brainstem nuclei of the so-called 'gain setting' or 'level setting' system, which influence arousal/attention (stage 2), are already involved. The locus coeruleus (LC), which is the largest noradrenergic nucleus in the brain, projects diffusely to all regions of the cerebral cortex. Thus loss or reduction of tyrosine hydroxylase activity and neuronal loss or axonopathy within the LC and catecholaminergic tract during PD can contribute to the development of attentional and cognitive changes.

embedded in polyethylene glycol and sectioned at $100 \mu \mathrm{m}$. An additional set of three tissue blocks, including the hippocampus at the level of the uncus, the striate area and the LC, also underwent polyethylene glycol embedding and sectioning at $100 \mu \mathrm{m}$ before staging for $\mathrm{AD}$ related neurofibrillary lesions and amyloid- $\beta$ plaque deposition, as published previously. ${ }^{114} 115 \mathrm{~A}$ diagnosis of $\mathrm{AD}$ was made when cognitive decline or dementia had been observed by the attending neurologists and when the degree of AD related neuropathology seen indicated the existence of a least a moderate likelihood for $\mathrm{AD}$ in accordance with the National Institute on Aging-Reagan criteria. ${ }^{116}$

\section{Case No 1}

Case No 1 is a 71-year-old woman with a disease duration of 15 years, whose prodromal symptoms included left-sided shoulder pain, an aching left hand, nightly quivering of the left lower extremity in bed (possibly consistent with restless legs syndrome $)^{117}$ and nocturnal insomnia. Five years after the initial PD diagnosis (she originally presented with unsteady turns, a left-sided resting tremor and bradykinesia of the left hand), her family noticed cognitive dysfunction in the form of increasing forgetfulness, confusion and spatial disorientation. She could not number the clock during testing. She experienced hallucinations, and her neurologist pondered the possibility of concomitant dementia. One year later, the same neurologist noted "mental status abnormalities probably early senile dementia of the Alzheimer's-type." At this point, she had already suffered from dyskinesia and two falls with resultant fractures but she refused deep brain stimulation. A follow-up visit after 2 months revealed unsteadiness of gait, hypophonia, sialorrhoea and urinary urgency accompanied by mild depression and mildly impaired recent memory but no hallucinations. Her decline became more rapid during the last 8 months of life: Hoehn and
Yahr stage 4, levodopa related motor fluctuations, severe dyskinesia with unwanted weight loss, hallucinations and agitation. When last evaluated 4 months prior to death, the patient required assistance with dressing and bathing, eating and toileting (urinary and faecal incontinence). She was wheelchair bound with severe dyskinesia, sialorrhoea, dysphagia (choking while eating), further unwanted weight loss, agitation and frequent hallucinations. She was disoriented to time and could not solve complex problems.

At autopsy, this patient's brain showed mild arteriosclerosis in the circle of Willis, PD stage 6 lesions, ${ }^{22}$ neurofibrillary tangle (NFT) stage $\mathrm{V}^{114}$ and stage 2 amyloid- $\beta$ deposition ${ }^{85} 115$ (figure 3A, B). In the lower brainstem, the LC of this patient had been badly damaged not only by a late stage synucleinopathy (figure $3 \mathrm{E}$ ) but also by a late stage tauopathy (AD) ${ }^{118}$ (figure $3 \mathrm{~F}$ ). In addition, a second dementing tauopathy was present, AGD: AT8 immunopositive oat shaped pathologically changed axons were present in the upper raphe nuclei, pigmented parabrachial nuclei, amygdala, hypothalamus (lateral tuberal nucleus) and especially in the entorhinal cortex (figure 3C, D) and hippocampal formation of the anteromedial temporal lobe. Thus the causes of her dementia were threefold: PD, AD and AGD.

As in the case of the previous individual, each of the following three patients who experienced cognitive decline and dementia subsequent to manifesting classical motor symptoms during the course of PD also suffered from one or more parasomnias (eg, REM sleep behaviour disorder, nocturnal insomnia and intrusion of daytime sleep attacks). The literature regarding sleep disorders in PD is large and testifies to the fact that abnormalities within most arousal systems not only can precede but also can accompany motor as well as cognitive changes. The neuroanatomical substrates of cognition and sleep/arousal include the hypothalamus, PPN and LC. 27384463 119-123 125 


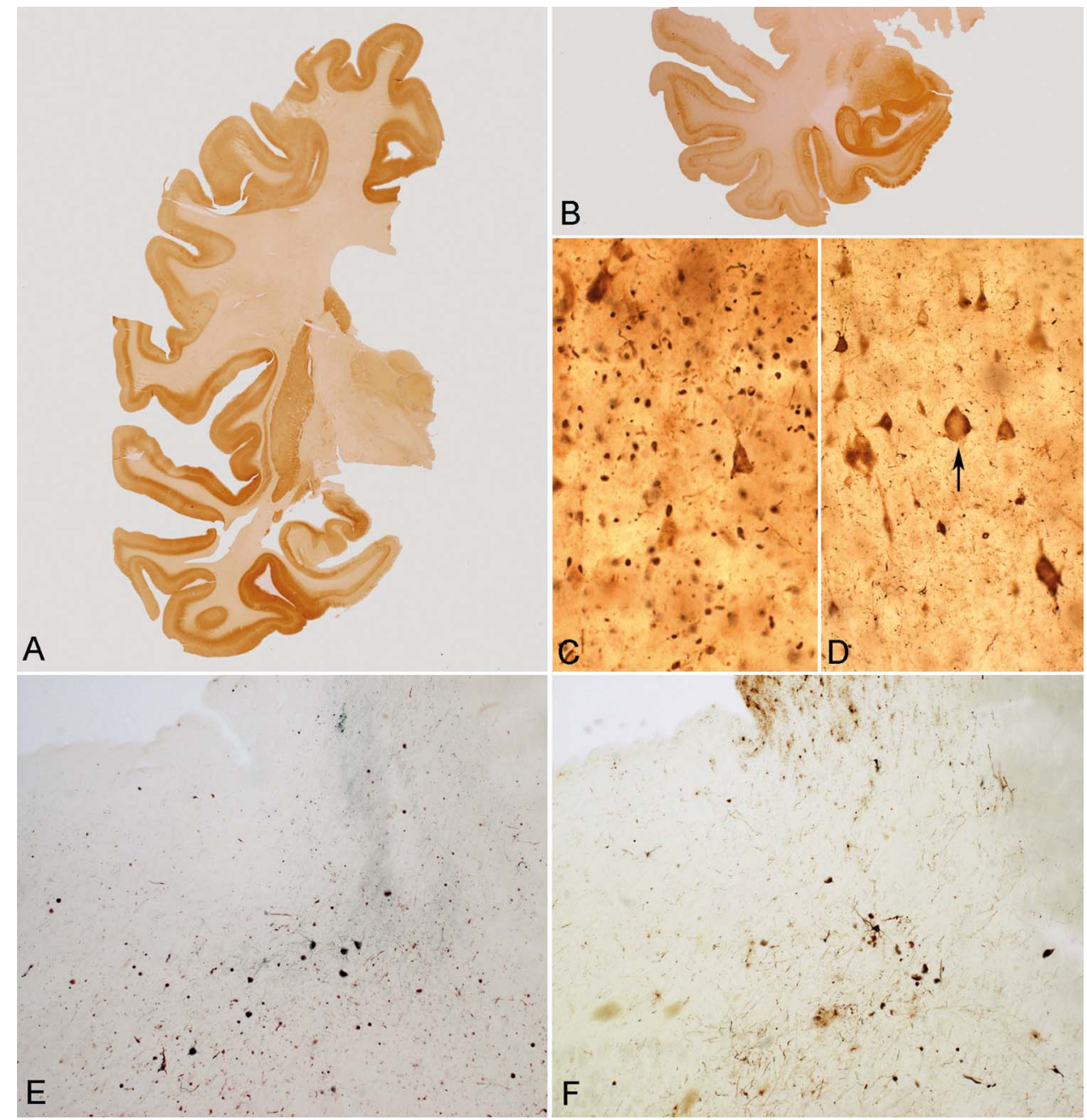

Figure 3 Tissue sections from a demented 71 -year-old woman (case No 1) with Parkinson's disease (PD) (A, E), Alzheimer's disease (AD) (B, F) and argyrophilic grain disease (AGD) (C, D). In hemisphere sections, this patient's brain revealed she had reached PD stage 6 (A) and neurofibrillary tangle stage V (B). (C, D) Micrographs show AT8 immunoreactive grains in the entorhinal cortex near the transentorhinal-entorhinal border. The distribution pattern and shapes of the comma or oat-shaped grains indicate that they are most probably pathologically altered axons. Because most of the abnormal tau is abnormally phosphorylated but non-argyrophilic, AT8 immunoreactions are required for recognition of the tau lesions-that is, practically speaking, 'pre-grains'. Arrow in (D) points to a ballooned achromatic (ie, lacking Nissl material) pyramidal cell. Ballooned cells are not only AT8 immunopositive but also immunoreactive for the heat shock protein $\alpha$-B-crystallin. The presence of such ballooned cells confirms the AGD diagnosis and helps to distinguish it from cases with 'pure' AD. (E, F) Micrographs showing severe neuronal loss within the locus coeruleus (LC) as well as Lewy pathology (E) and AT8 immunoreactive pretangle material (F). Compare the aspect of the LC here with that in a gender and age matched case shown in figure 5C. Immunoreactions for $\alpha$-synuclein (A), $\alpha$-synuclein plus tyrosine hydroxylase (E) and AT8 (B, F) in $100 \mu \mathrm{m}$ sections.

\section{Case No 2}

Case No 2 is a 74-year-old man with a disease duration of nearly 7 years and a history of REM sleep behaviour disorder (RBD) beginning at age 66 years. ${ }^{126-131}$ Two years after developing $\mathrm{RBD}$, his neurologist noted a clinical presentation compatible with PD: bent posture, hypophonia and hypomimia accompanied by a bilateral resting tremor, asymmetric mild cogwheel rigidity, apathy and bradyphrenia. Up to that point there were no hallucinations or measurable cognitive impairment (Mini-Mental State Examination (MMSE) score 27/30) and the patient's independent activities of daily life (ADLs) were intact. Six years after developing RBD, the patient's wife reported her husband was becoming increasingly forgetful and that his motor functions (gait, speech) as well as his cognitive skills were declining gradually but steadily. During the following period, he experienced difficulties eating, unwanted weight loss, urinary incontinence and periodic visual hallucinations. In the end, he could no longer bathe, dress, eat or drink independently. His MMSE score 4 months prior to death was 14/30.
At autopsy, the patient's brain revealed mild vascular changes accompanied by lesions compatible with NFT stage III $^{114}$ (figure 4B, D), stage 3 amyloid- $\beta$ deposition ${ }^{85} 115$ and PD stage $6^{22}$ (figure $4 \mathrm{~A}, \mathrm{C}$ ). Thus, owing to the presence of the concomitant pathologies in the anteromedial temporal lobe, a limbic transitional portion of the cortex that is necessary for intact cognition, we made the diagnoses PD and AD. ${ }^{70} 132133$ Moreover, the LC of this patient was also severely affected by the PD associated pathological process: figure $5(\mathrm{~A}, \mathrm{~B})$ shows not only the presence of LP but also sharply depleted TH immunoreactivity accompanied by heavy noradrenergic cell loss (compare age matched control in figure $5 \mathrm{C}$ ).

\section{Case No 3}

Case No 3 is an 88-year-old man with a disease duration of 12 years whose prodromal symptoms included micrographia, stooped posture and arthritic-like pain. At the age of 76 years when PD was initially diagnosed, his ADLs were intact, but he reported occasional yelling and violent kicking in bed at night 
Figure 4 Hemisphere sections from a demented 74-year-old man (case No 2) with Parkinson's disease (PD) (A, C) and Alzheimer's disease (B, D). In an immunoreaction directed against $\alpha$-synuclein, it is evident even without the aid of a light microscope that the amygdala $(A)$ and all fields of the entire cerebral cortex $(C)$ had become involved in the PD-related pathological process (stage 6). But this patient was also at neurofibrillary tangle stage III $(B, D)$, as seen using AT8 immunohistochemistry. $100 \mu \mathrm{m}$ sections.

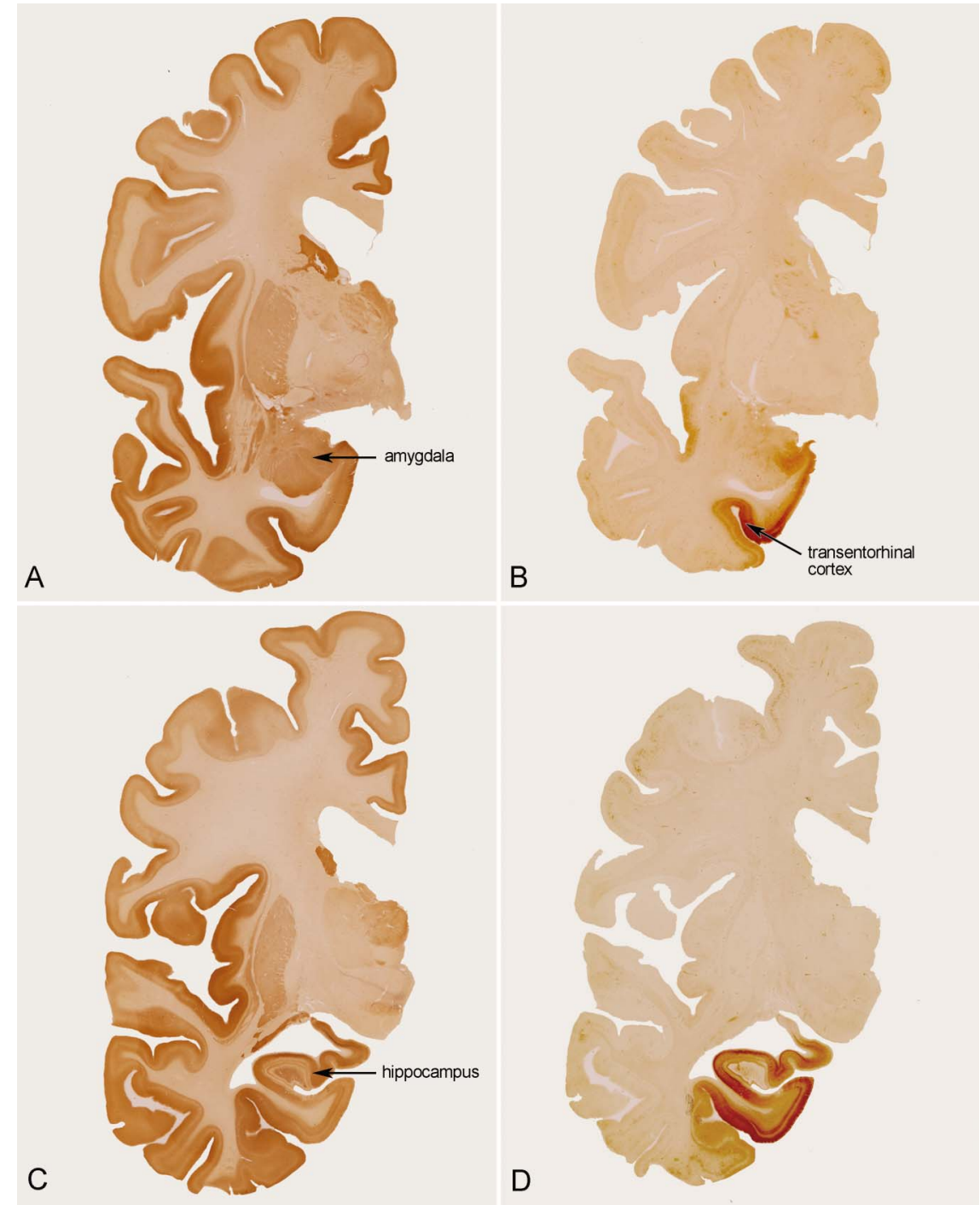

(compatible with or indicative of RBD?), slowness of gait, a loss of left-handed strength, persistent micrographia and constipation. He presented with dysarthria, slight postural instability and mild rigidity of the right upper and lower extremities but no resting tremor. ${ }^{134}$ The neurologist noted mild depression and cognition well within the normal range. Later that same year and during the following 3 years, repeated complaints of falls (possibly in connection with orthostatic failure), extreme fatigue evenings, nightly sleep attended by quivering and jerking of the patient's feet, and daytime sleep attacks (son: "father sometimes falls asleep while playing golf”). ${ }^{135}$

Five years after receiving the diagnosis idiopathic PD, both the patient's family and the attending neurologist noticed the beginning of cognitive dysfunction in the form of forgetfulness, disorientation and poor judgment. Frequent falls resulted in facial injuries (eg, six in a 2-month period), and the patient occasionally choked on food. He also began experiencing some hallucinations, reporting sensations of having 'someone present'. The last 6 years of life were marked by increasing memory impairment, intermittent hallucinations and paranoid delusions, but above all by decreasing mobility owing to bradykinesia, an unsteady gait and poor balance. His wife reported 5-6 falls monthly owing to a loss of balance, freezing in doorways and when turning, but no motor fluctuations or tremor. Minimal assistance with ADLs was required (showering, toileting). The patient became increasingly disoriented with regard to dates, his own street address and name/word recall, and had difficulty with clock drawing (MMSE 20/30). The neurologists revised their earlier diagnosis to 'dementia with diffuse Lewy bodies'. Following nursing home placement owing to frequent falls and severely impaired cognition, the patient experienced vivid dreams, hallucinations/delusions, depression and, increasingly, dyskinesias. He spent most of his time in a wheelchair and had not walked for 3 months when his wife saw him for the last time.

Post mortem examination revealed PD stage 5 brain pathology, ${ }^{22}$ NFT stage IV, ${ }^{109}$ stage 0 amyloid- $\beta$ plaque deposition $^{85} 115$ and severe atherosclerosis of the circle of Willis. As in the preceding case, the patient's history was remarkable in that he had suffered from RBD prior to the onset of PD. Moreover, late in life, he had experienced two transient ischaemic attacks within a 3 year period. In other words, this patient had PD and AD accompanied by cerebrovascular disease.

By contrast, a smaller subset of patients display cognitive decline/dementia primarily or chiefly attributable to the distribution pattern and severity of PD related LP alone (ie, PDD). ${ }^{83}$ The following case represents such an individual.

\section{Case No 4}

Case No 4 is an 82-year-old man with a 10 year duration of disease. The clinical records dating from the time around the 
Figure 5 (A, B) Section from the locus coeruleus of the same patient as in figure $4((B)$ represents the framed area in (A) at higher magnification). Note not only the dystrophic Lewy neurites (LN) in (B) but also the relative paucity of tyrosine hydroxylase (TH) immunoreactivity and melanised neurones in (A), as opposed to the situation in an age-matched control in (C). Immunoreactions for $\alpha$-synuclein plus TH in $100 \mu \mathrm{m}$ sections. (D-F) Micrographs of the catecholaminergic tract (and locus coeruleus in (D) at the right) from an 82-year-old demented woman (case No 5) with Parkinson's disease, Alzheimer's disease and cerebrovascular disease. (E) represents the framed area in (D) (overview) at higher magnification: there is loss of TH immunoreactivity within the tract accompanied by the presence of LNs. (F) Arrows point to a few weakly TH immunoreactive axons of normal calibre. At the lower left, the axonal segments containing LNs are swollen and the axon itself is devoid of $\mathrm{TH}$ immunolabelling. Immunoreactions for $\alpha$-synuclein plus TH in $100 \mu \mathrm{m}$ sections.

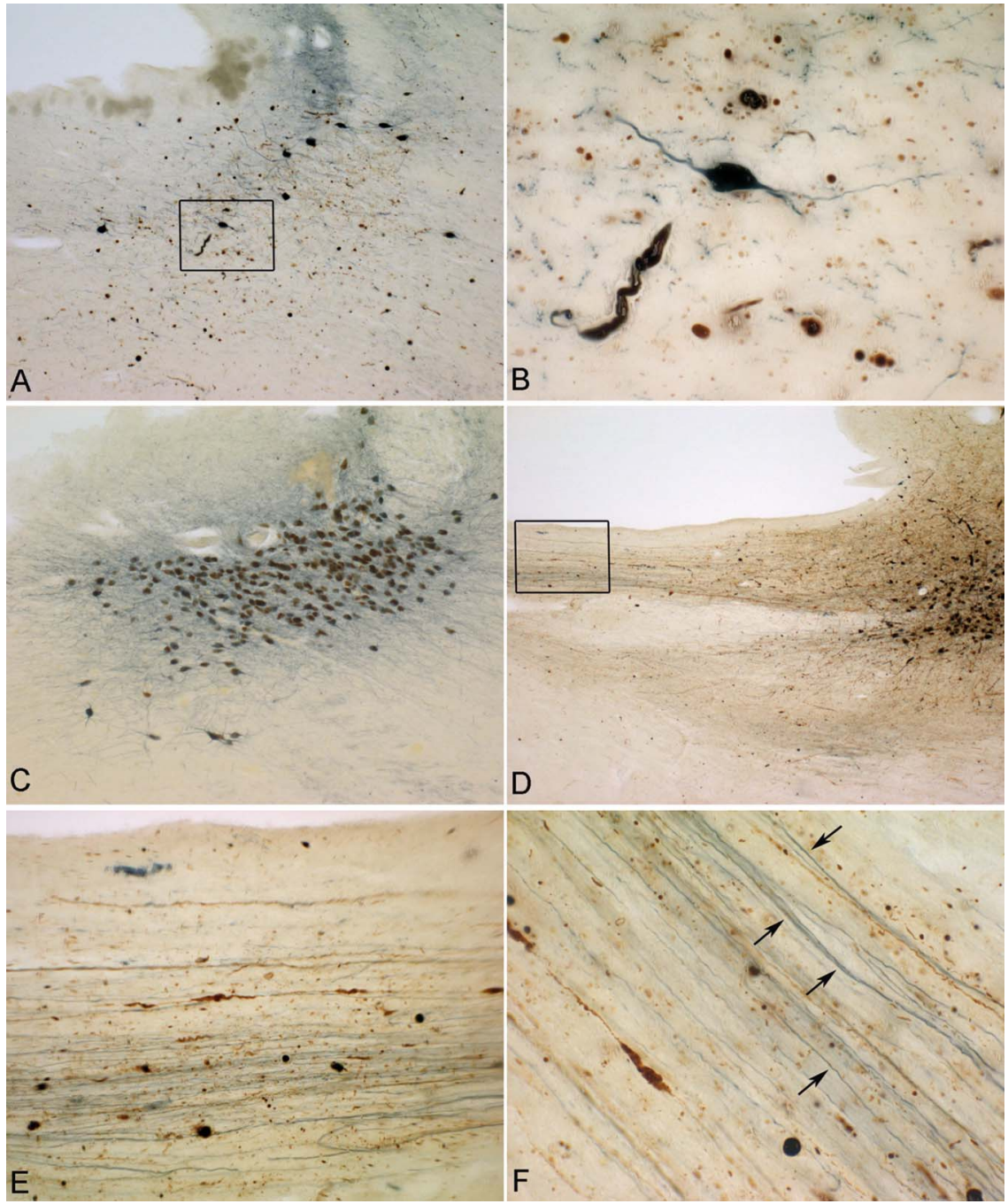

PD diagnosis noted the presence of dysarthria, micrographia, difficulty arising from chairs, a shuffling gait and lack of balance on stairs, and nightly nocturia, but no cognitive problems. A right-handed resting tremor manifested itself the following year. In addition to motor and wearing off symptoms, the patient subsequently developed nocturnal insomnia and excessive daytime sleepiness attacks resulting in a minor car accident, ${ }^{135}$ and he eventually underwent arthroplastic surgery for persistent right-sided shoulder pain. Shortly thereafter he began complaining of unwanted weight loss with decreasing muscle mass (eventually $15 \mathrm{lbs}$ over a 2 year period despite a hearty appetite). ${ }^{136}$ Seven years after the initial PD diagnosis, the patient reported troubling incidents of obsessive sexual thoughts and sexually inappropriate behaviour (repeatedly disrobing in public places). According to his spouse, his loss of inhibition generally occurred and even increased in the evenings. He was prescribed an antidementia medication and considered, but did not initiate, oestrogen therapy to reduce his sexually obsessive behaviour. Late in the disease course, he suffered frequent auditory hallucinations and paranoid delusions, vivid nightmares and moderate bradykinesia without dyskinesia. Shortly before transferring to a residential care facility where the patient died several months later, the attending neurologist noted "PD with Lewy body dementia manifested by cognitive slowing, psychosis and inappropriate sexual behaviour".
At autopsy, the patient's brain displayed lesions compatible with PD stage $4,{ }^{22}$ NFT stage II $^{114}$ and amyloid- $\beta$ desposition stage $0 .{ }^{85} 115$ In view of this patient's clinical course, low cortical NFT as well as amyloid- $\beta$ deposition stages, and the notable absence of any cerebrovascular disease, we attributed his dementia to subcortical (ie, brainstem) and cortical (limbic) PD (figure 6A). Medial sagittal sections immunostained for aggregated $\alpha$-synuclein showed the presence and effects of LP at all levels of the LC along its entire column-like extent (figure 6B). The patient's clinical course was particularly remarkable in that most of his socially disruptive behaviour (eg, undressing completely and exercising on the front porch where he could be seen by others) occurred chiefly late evenings-such forms of disruptive nocturnal activity, in this case accompanied by an compulsive element, are somewhat reminiscent of 'sundowning', which may be more widespread in PDD than in AD. ${ }^{137}$

\section{Case No 5}

Case 5 is an 82-year-old woman with a disease duration of nearly 8 years, who initially presented with hypophonia and a mild right-handed resting tremor with right-handed bradykinesia and slight cogwheel rigidity. Late the following year, her parkinsonism was assessed as Hoehn and Yahr stage 3 and her ADLs were intact. Over the next 4 years, the patient was able to live independently but then began experiencing episodic visual 
Figure 6 Tissue sections from an 82-year-old man (case No 4) with Parkinson's disease (PD) dementia. (A) As shown by the extent of the Lewy pathology (LP) (involvement of the anteromedial and basal temporal cortex), this patient had reached PD stage 4. (B) Note also, however, that the entire locus coeruleus is filled with LP. Immunoreactions for $\alpha$-synuclein in $100 \mu \mathrm{m}$ sections.

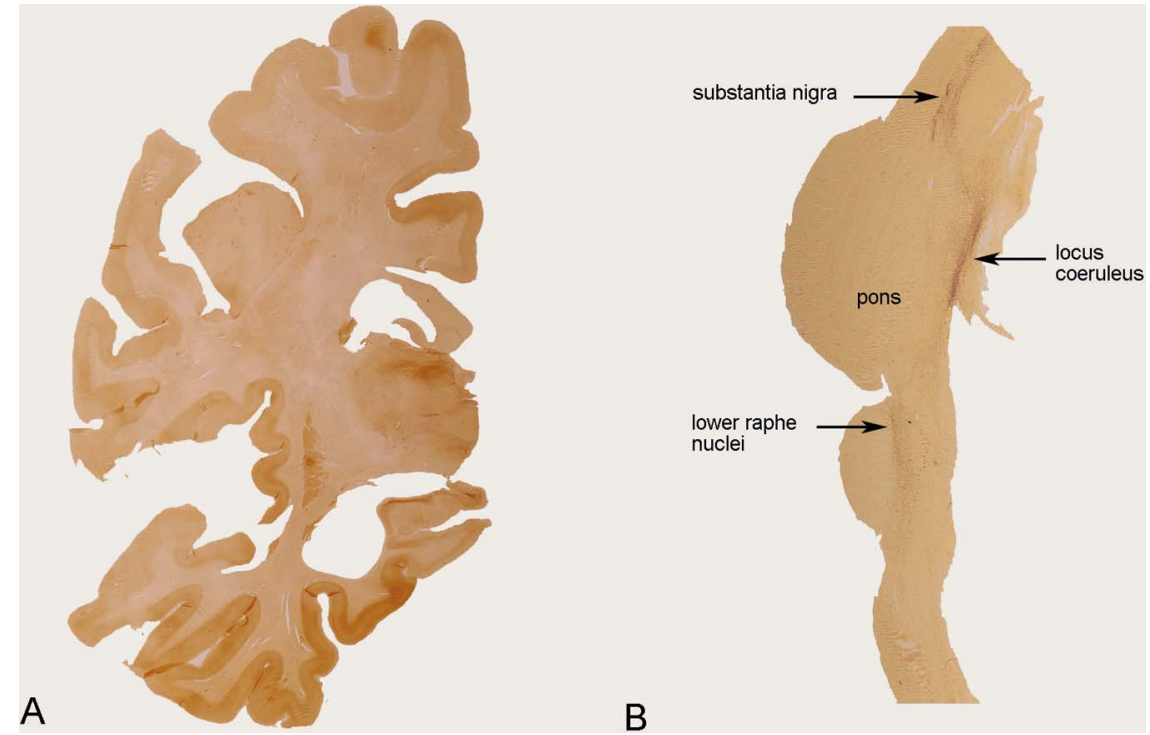

hallucinations, and her husband noticed cognitive dysfunction in the form of increasing forgetfulness. Her neurologists considered 'PDD' or 'PD and dementia of the Alzheimer's-type' (MMSE 20/ 30). A single photon emission CT imaging examination 1 year later showed vascular changes in both temporal lobes as well as frontally (left hemisphere). During the later disease course, the patient hallucinated more frequently but also with paranoid content, and her cognition worsened. She became confused, apathetic and was mildly depressed. The patient transferred to a nursing home owing to her continuing decline in short term memory and disorientation to time as well as increasing need for assistance (bathing, toileting). She suffered from urinary incontinence, choking incidents when swallowing, motor fluctuations and frequent hallucinations. She became wheelchair bound (Hoehn and Yahr stage 5) and died of pneumonia less than a year after being admitted to resident nursing care.

At autopsy, the patient's brain showed moderate vascular changes (arteriosclerosis of the circle of Willis, widespread amyloid angiopathy) accompanied by lesions compatible with NFT stage III, ${ }^{114}$ stage 3 amyloid- $\beta$ deposition ${ }^{85} 115$ and PD neuropathological stage $6 .^{22}$ In addition, LP was also present in the following central and peripheral nervous system sites: intermediolateral (IML) column, superior cervical ganglion (SCG), cervical sympathetic chain, submandibular gland, Auerbach plexus of the distal oesophagus and stomach, and peripheral vagal nerve.

Frontal sections through the LC and catecholaminergic tract double immunostained for aggregated $\alpha$-synuclein, and $\mathrm{TH}$ showed not only severe neuronal and TH loss in the LC but also the presence of LNs in axons of the catecholaminergic tract and a severe TH deficiency we have not encountered in control individuals (figure 5D-F). This patient's final neuropathological diagnoses included PD, $\mathrm{AD}$ and cerebrovascular disease. Although we cannot know for certain at this point, it seems reasonable to conclude that the lesions in the LC and catecholaminergic tract of this patient more than likely exacerbated (rather than attenuated) her risk for developing cognitive decline and dementia.

In the autonomic nervous system, preganglionic sympathetic (noradrenergic) nerve fibres from segments $1-4$ in the IML nucleus of the thoracic spinal cord and within the paravertebral sympathetic chain synapse on three cervical ganglia, whereby the last of these, the inferior cervical ganglion, is often fused with the first thoracic ganglion to form the stellate ganglion. The SCG reaches indirectly (via the internal carotid plexus) or directly all cranial nerves except for the first, second and eighth; moreover, it innervates the first to fourth or fifth cervical spinal nerves. $^{138-140}$

In addition to the pineal gland (LP has not been found there to date; authors' unpublished data), the SCG innervates the orbital muscle, iris (dilator pupillae muscle), the nasal cavity, major salivary glands, oropharynx, larynx, thyroid gland and the heart. ${ }^{141-}$ 146 Thus the presence of $\alpha$-synuclein immunoreactive lesions within the IML, SCG, submandibular gland, larynx and cardiac nerves in early and late phase PD $^{3} 671931147$ coupled with the existence of abnormalities in salivary production, swallowing, phonation and sympathetic heart rate variability ${ }^{148-160}$ make it reasonable to posit that compromised cellular and/or axonal integrity, wherever it occurs within the circuitry of the same anatomically functional system (eg, IML $\rightarrow$ SCG $\rightarrow$ target organ), likely contribute to neurodegeneration and autonomic dysfunction within that system. ${ }^{6} 26161$

Notably, two of the SCG's four postganglionic sympathetic efferent branches are responsible for vasoconstriction in the meningeal arteries of the posterior cranial fossa as well as for vasoconstriction in the anterior, middle and posterior cerebral arteries. Furthermore, if one recalls that the LC contributes to the modulation of local blood flow via the paracrine release of norepinephrine acting on astrocytes and non-neuronal cells near the cerebral microvasculature, ${ }^{44} 58162163$ then a chronic TH deficiency or noradrenergic inhibition within the LC-norepinephrine system as well as the LP related degeneration of the SCG might increase the development of cerebral hypoperfusion associated cognitive decline. ${ }^{164-167}$

\section{CONCLUDING REMARKS}

Recent research has furnished evidence of axonal and neuronal dysfunction in neuromelanised projection cells within the LC, not only in the form of diminished $\mathrm{TH}$ immunoreactivity within neuronal processes containing LNs (figure 5E, F) and within the neuronal cytoplasm (figure 1D) but also in the form of $\mathrm{TH}$ - neurotransmitter sequestered within immunolabelled LNs and somatic $\mathrm{LBs}^{37}$ (figure 1D-F, arrows). Loss of $\mathrm{TH}$ immunoreactivity in cellular somata and in neuronal processes and/or the presence of $\mathrm{TH}$ immunolabelling in LBs of the coeruleus noradrenergic nerve cells strongly indicate that, at least in 
this brainstem nucleus, the PD associated lesions are pathogenic rather than neuroprotective.

Despite the considerable role of the LC-norepinephrine system, the contribution of noradrenergic deficit (eg, TH metabolic deficits in the LC, the leading source of noradrenergic innervation in the brain) to cognitive dysfunction in PD, with some exceptions, is still underappreciated. ${ }^{24} \quad 61 \quad 83 \quad 168-172$ Progress in the development of noradrenergic therapeutic interventions might not only alleviate depressive and/or anxiety symptoms ${ }^{42} 44$ but possibly also delay dementia onset. ${ }^{170}$ Finally, studies devoted to the role not only of LP related dysfunction within the LC but also within related autonomic neurocircuitry (IML, SCG) to concomitant neurodegenerative pathologies and their potential influence on the development of cerebrovascular disease during neurodegeneration are needed.

Acknowledgements The authors wish to thank Albert C Ludolph, MD (Director, Department of Neurology, University of UIm) for his ongoing support, The Braak Collection (Goethe University Frankfurt), James William Langston, MD (The Parkinson's Institute, Sunnyvale, California, USA) and Caroline Racine, PhD (University of California San Francisco) for supplying autopsy material. The authors acknowledge Ms Simone Feldengut (immunohistochemistry, Centre for Biomedical Research, University of Ulm) and Mr David Ewert (graphics, Department of Neurology, University of Ulm) for their technical expertise.

Contributors KDT: conception and organisation; writing of the first and revised manuscript drafts; and figures-layout. HB: conception and organisation; writing of the first and revised manuscript drafts; and digital photography.

Patient consent Obtained.

Funding This article was made possible by funding from the German Research Council (Deutsche Forschungsgemeinschaft, DFG, grant No TR 1000/1-1) and the Michael J Fox Foundation for Parkinson's Research (New York City, NY, USA).

Competing interests None.

Provenance and peer review Commissioned; externally peer reviewed.

\section{REFERENCES}

1 den Hartog Jager WA, Bethlem J. The distribution of Lewy bodies in the central and autonomic nervous systems in idiopathic paralysis agitans. J Neurol Neurosurg Psychiatry 1960;23:283-90.

2 Wakabayashi K, Takahashi H, Takeda S, et al. Parkinson's disease: the presence of Lewy bodies in Auerbach's and Meissner's plexuses. Acta Neuropathol 1988;76:217-21

3 Wakabayashi K, Takahashi H. The intermediolateral nucleus and Clarke's column in Parkinson's disease. Acta Neuropathol 1997;94:287-9.

4 Iwanaga K, Wakabayashi K, Yoshimoto M, et al. Lewy body-type degeneration in cardiac plexus in Parkinson's and incidental Lewy body diseases. Neurology 1999:52:1269-71.

5 Nolano M, Provitera V, Estraneo A, et al. Sensory deficit in Parkinson's disease: evidence of a cutaneous denervation. Brain 2008;131:1903-11.

6 Del Tredici K, Hawkes $\mathrm{CH}$, Ghebremedhin $\mathrm{E}$, et al. Lewy pathology in the submandibular gland of individuals with incidental Lewy body disease and sporadic Parkinson's disease. Acta Neuropathol 2010;121:703-13.

7 Cersósimo MG, Perandonas C, Micheli FE, et al. Alpha-synuclein immunoreactivity in minor salivary gland biopsies of Parkinson's disease patients. Mov Disord 2011;26:188-90.

8 Shannon KM, Deshavarzian A, Mutlu E, et al. Alpha-synuclein in colonic submucosa in early untreated Parkinson's disease. Mov Disord 2011;27:709-15

9 Spillantini MG, Schmidt ML, Lee VMY, et al. $\alpha$-Synuclein in Lewy bodies. Nature 1997;388:839-40.

10 Irizarry MC, Growdon W, Gómez-Isla T, et al. Nigral and cortical Lewy bodies and dystrophic nigral neurites in Parkinson's disease and cortical Lewy body disease contain $\alpha$-synuclein immunoreactivity. J Neuropathol Exp Neurol 1998;15:112-16.

11 Trojanowski JQ, Lee VM. Parkinson's disease and related neurodegenerative synucleinopathies linked to progressive accumulations of synuclein aggregates in the brain. Parkinsonism Relat Disord 2007;7:247-51.

12 Dickson DW, Braak H, Duda JE, et al. Neuropathological assessment of Parkinson's disease: refining the diagnostic criteria. Lancet Neurol 2009;8:1150-7.

13 Prasad K, Beach TG, Hedreen J, et al. Critical role for truncated $\alpha$-synuclein and aggregates in Parkinson's disease and incidental Lewy body disease. Brain Pathol doi: 10.1111/j.1750-3639.2012.00597.x

14 Braak H, Braak E, Yilmazer D, et al. Amygdala pathology in Parkinson's disease. Acta Neuropathol 1994;88:493-500.
15 Kanazawa T, Adachi E, Orimo $S$, et al. Pale neurites, premature $\alpha$-synuclein aggregates with centripetal extension from axon collaterals. Brain Pathol 2012;22:67-78.

16 Braak E, Sandmann-Keil D, Rüb U, et al. Alpha-synuclein immunopositive Parkinson's disease-related inclusion bodies in lower brain stem nuclei. Acta Neuropathol 2001;101:195-201.

17 Dale GE, Probst A, Luthert P, et al. Relationships between Lewy bodies and pale bodies in Parkinson's disease. Acta Neuropathol 1992;83:525-9.

18 Forno LS. Concentric hyalin intraneuronal inclusions of Lewy type in the brain of elderly persons (50 incidental cases): relationship to parkinsonism. J Am Geriatr Soc 1969;17:557-75

19 Forno LS, Norville RL. Ultrastructure of Lewy bodies in the stellate ganglion. Acta Neuropathol 1976;34:183-97.

20 Halliday GM, Li YW, Blumbergs PC, et al. Neuropathology of immunohistochemically identified brainstem neurons in Parkinson's disease. Ann Neurol 1990;27:373-85.

21 German DC, Manaye KF, White CL 3rd. Disease-specific patterns of locus coeruleus cell loss. Ann Neurol 1992;32:667-76.

22 Braak H, Del Tredici K, Rüb U, et al. Staging of brain pathology related to sporadic Parkinson's disease. Neurobiol Aging 2003;24:197-210.

23 Zarow C, Lyness SA, Mortimer JA, et al. Neuronal loss is greater in the locus coeruleus than nucleus basalis and substantia nigra in Alzheimer and Parkinson diseases. Arch Neurol 2003:60:337-41.

24 Brünnstrom $\mathrm{H}$, Friberg $\mathrm{N}$, Lindberg $\mathrm{E}$, et al. Differential degeneration of the locus coeruleus in dementia subtypes. Clin Neuropathol 2011;30:104-10.

25 McMillan PJ, White SS, Franklin A, et al. Differential response of the central noradrenergic nervous system to the loss of locus coeruleus neurons in Parkinson's disease and Alzheimer's disease. Brain Res 2011;1373:240-52.

26 Del Tredici K, Braak H. Lewy pathology and neurodegeneration in premotor Parkinson's disease. Mov Disord 2012;27:597-607.

27 Dugger BN, Murray ME, Boeve BR, et al. Neuropathological analysis of brainstem cholinergic and catecholaminergic nuclei in relation to rapid eye movement (REM) sleep behaviour disorder. Neuropathol Appl Neurol 2012;38:142-52.

28 Del Tredici K, Rüb U, de Vos RAl, et al. Where does Parkinson disease pathology begin in the brain? J Neuropathol Exp Neurol 2002;61:413-26.

29 Bloch A, Probst A, Bissig $H$, et al. $\alpha$-Synuclein pathology of the spinal and peripheral autonomic nervous system in neurologically unimpaired elderly subjects. Neuropathol App/ Neurobiol 2006;12:284-95.

30 Markesbery WR, Jicha GA, Liu $\mathrm{H}$, et al. Lewy body pathology in normal elderly subjects. J Neuropathol Exp Neurol 2009;68:816-22.

31 Miki Y, Mori F, Wakabayashi K, et al. Incidental Lewy body disease restricted to the heart and stellate ganglion. Mov Disord 2009;24:2299-301.

32 Dickson DW, Uchikado $\mathrm{H}$, Fujishiro $\mathrm{H}$, et al. Evidence in favor of Braak staging of Parkinson's disease. Mov Disord 2010;25(Suppl 1):S78-82.

33 van de Berg WD, Hepp DH, Dijkstra AA, et al. Patterns of alpha-synuclein pathology in incidental cases and clinical subtypes of Parkinson's disease. Parkinsonsim Relat Disord 2012;18(Suppl 1):S28-30.

34 Mitsui J, Saito Y, Momose T, et al. Pathology of the sympathetic nervous system corresponding to the decreased cardia uptake in $123^{\prime}$-metaiodobenzylguanidine (MIBG) scintigraphy in a patient with Parkinson disease. J Neurol Sci 2006;243:101-4.

35 Orimo S, Uchihara T, Nakamura A, et al. Axonal alpha-synuclein aggregates herald centripetal degeneration of cardiac sympathetic nerve in Parkinson's disease. Brain 2008:131:642-50.

36 Dickson DW, Fujishiro H, DelleDonne A, et al. Evidence that incidental Lewy body disease is pre-symptomatic Parkinson's disease. Acta Neuropathol 2008;115:437-44.

37 Dugger BN, Dickson DW. Cell type specific sequestration of choline acetyltransferase and tyrosine hydroxylase within Lewy bodies. Acta Neuropathol 2010;120:633-9.

38 Berridge CW, Waterhouse BD. The locus coeruleus-noradrenergic system: modulation of behavioral state and state-dependent cognitive processes. Brain Res Rev 2003:42:33-84.

39 Dahlström A, Fuxe K. Evidence for the existence of monoamine-containing neurons in the central nervous system. I. Demonstration of monoamines in the cell bodies of brain stem neurones. Acta Physiolog Scand 1964;62(Suppl 232): $1-55$.

40 Foote SL, Bloom FE, Aston-Jones G. Nucleus locus ceruleus: new evidence of anatomical and physiological specificity. Physiol Rev 1983;63:844-914.

41 Halliday GM. Substantia nigra and locus coeruleus. In: Paxinos G, Mai JK, eds The human nervous system. 2nd edn. San Diego: Academic Press, 2004: 677-738.

42 Bremner JD, Krystal JH, Southwick SM, et al. Noradrenergic mechanisms in stress and anxiety: I. Preclinical studies. Synapse 1996;23:28-38.

43 Aston-Jones G, Cohen JD. Adaptive gain and the role of the locus coeruleusnorepinephrine system in optimal performance. J Comp Neurol 2005:493:99-110.

44 Benarroch EE. The locus ceruleus norepinephrine system: functional organization and potential clinical significance. Neurology 2009;73:1699-704. 
45 Holstege G. Subcortical limbic system projections to caudal brainstem and spinal cord. In: Paxinos G, ed. The Human nervous system. San Diego: Academic Press, 1990:261-86.

46 Holstege G. The somatic motor system. Prog Brain Res 1996;107:9-26.

47 Nieuwenhuys $R$. The greater limbic system, the emotional motor system and the brain. Prog Brain Res 1996;107:551-80.

48 Braak H, Rüb U, Sandmann-Keil D, et al. Parkinson's disease: affection of brain stem nuclei controlling premotor and motor neurons of the somatomotor system. Acta Neuropathol 2000;99:489-95.

49 Millan MJ. Descending control of pain. Prog Neurbiol 2002;66:355-474.

50 Samuels ER, Szabadi E. Functional neuroanatomy of the noradrenergic locus coeruleus: its role in the regulation of arousal and autonomic function Part l: principles of functional organisation. Curr Neuropharmacol 2008;6:235-53.

51 Raichle ME, Hartmann BK, Eichling JO, et al. Central noradrenergic regulation of cerebral blood flow and vascular permeability. Proc Natl Acad Sci USA 1975;72:3726-30.

52 Edvinsson L, Owman C, Sjöberg N-O. Autonomic nerves, mast cells, and amine receptors in human brain vessels. A histochemical and pharmacological study. Brain Res 1976:115:377-93.

53 Amaral DG, Sinnamon HM. The locus coeruleus: neurobiology of a central noradrenergic nucleus. Prog Neurobiol 1977;9:147-96.

54 Hartman BK, Swanson LW, Raichle ME, et al. Central adrenergic regulation of cerebral microvascular permeability and blood flow; anatomic and physiologic evidence. Adv Exp Med Biol 1980;131:113-26.

55 Palmer GC. Neurochemical coupled actions of transmitters in the microvasculature of the brain. Neurosci Biobehav Rev 1986;10:79-101.

56 Kalaria RN, Stockmeier CA, Harik SI. Brain microvessels are innervated by locus ceruleus noradrenergic neurons. Neurosci Lett 1989;97:203-8.

57 Waterhouse BD, Devilbiss D, Fleischer $D$, et al. New perspectives on the functional organization of postsynaptic influences of the locus ceruleus efferent projection system. Adv Pharmacol 1998;42:749-54

58 Hamel E. Perivascular nerves and the regulation of cerebrovascular tone. J App/ Physiol 2006;100:1059-64.

59 McNaughton N, Mason ST. The neuropsychology and neuropharmacology of the dorsal ascending noradrenergic bundle-a review. Prog Neurobiol 1979;14:157-219.

60 Bates D, Weinshilboum RM, Campbell RJ, et al. The effect of lesions in the locus coeruleus on the physiological responses of the cerebral blood vessels in cats. Brain Res 1977:136:141-3.

61 Jellinger K. Morphological substrates of mental dysfunction in Lewy body disease: an update. J Neural Trans Supp/ 2000;59:185-212.

62 Sara SJ. The locus coeruleus and noradrenergic modulation of cognition. Nat Rev Neurosci 2009:10:211-23.

63 Thannickal TC, Lai YY, Siegel JM. Hypocretin (orexin) cell loss in Parkinson's disease. Brain 2007:130:1586-95.

64 Jellinger K. The pedunculopontine nucleus in Parkinson's disease, progressive supranuclear palsy and Alzheimer's disease. J Neurol Neurosurg Psychiatry 1988;51:540-3.

65 Pahapill PA, Lozano AM. The pedunculopontine nucleus and Parkinson's disease. Brain 2000;123:1767-83.

66 Steckler T, Inglis W, Winn P, et al. The pedunculopontine tegmental nucleus: a role in cognitive processes? Brain Res Rev 1994;19:298-318.

67 Jenkinson N, Nandi D, Muthusamy K, et al. Anatomy, physiology, and pathophysiology of the pedunculopontine nucleus. Mov Disord 2009;24:319-28.

68 Zweig RM, Jankel WR, Hedreen JC, et al. The pedunculopontine nucleus in Parkinson's disease. Ann Neurol 1989:26:41-6.

69 Rinne JO, Ma SY, Lee MS, et al. Loss of cholinergic neurons in the pedunculopontine nucleus in Parkinson's disease is related to disability of the patients. Parkinsonism Relat Disord 2008:14:553-7.

70 Braak H, Del Tredici K. Neuroanatomy and pathology of sporadic Parkinson's disease. Adv Anat Embryol Cell Biol 2009;201:1-119.

71 Aarsland D, Andersen K, Larsen JP, et al. Prevalence and characteristics of dementia in Parkinson's disease: an 8-year prospective study. Arch Neurol 2003;60:387-92.

72 Galvin JE, Pollack J, Morris JC. Clinical phenotype of Parkinson disease dementia. Neurology 2006;67:1605-11.

73 Emre M, Aarsland D, Brown R, et al. Clinical diagnostic criteria for dementia associated with Parkinson's disease. Mov Disord 2007;22:1689-707.

74 Dubois B, Burn D, Goetz C, et al. Recommendations from the Movement Disorder Society Task Force. Mov Disord 2007:22:2314-24.

75 Buter TC, van den Hout A, Matthews FE, et al. Dementia and survival in Parkinson's disease: a 12-year population study. Neurology 2008;70:1017-22.

76 Hely MA, Reid WG, Adena MA, et al. The Sydney multicenter study of Parkinson's disease: the inevitability of dementia at 20 years. Mov Disord 2008:23:837-44.

77 Reid WG, Hely MA, Morris JG, et al. Dementia in Parkinson's disease: a 20-year neuropsychological study (Sydney Multicentre Study). J Neurol Neurosurg Psychiatry 2011:82:1033-7.
78 Colosimo C, Hughes AJ, Kilford L, et al. Lewy body cortical involvement may not always predict dementia in Parkinson's disease. J Neurol Neurosurg Psychiatry 2003;74:852-6.

79 Lippa CF, Duda JE, Grossman M, et al. DLB and PDD boundary issues: diagnosis, treatment, molecular pathology, and biomarkers. Neurology 2007;68:812-19.

80 Poewe W. Non-motor symptoms in Parkinson's disease. Eur J Neurol 2008;15 (Suppl 1):14-20.

81 McKeith IG, Dickson DW, Lowe J, et al. Diagnosis and management of dementia with Lewy bodies: third report of the DLB Consortium. Neurology 2005:65:1863-72.

82 Jellinger KA, Morphological substrates of dementia in parkinsonism. A critical update. J Neural Transm Supp/ 1997:51:57-82.

83 Braak H, Rüb U, Jansen Steur EN, et al. Cognitive status correlates with neuropathologic stage in Parkinson disease. Neurology 2005;64:1404-10.

84 Korczyn AD, Gurevich T. Parkinson's disease: before the motor symptoms and beyond. J Neurol Sci 2010;289:2-6.

85 Montine TJ, Phelps CH, Beach TG, et al. National Institute on Aging-Alzheimer's Association guidelines for the neuropathologic assessment of Alzheimer's disease: a practical approach. Acta Neuropathol 2012;123:1-11.

86 Hurtig HI, Trojanowski JQ, Galvin J, et al. Alpha-synuclein cortical Lewy bodies correlate with dementia in Parkinson's disease. Neurology 2000;54:1916-21.

87 Mattila PM, Rinne JO, Helenius $\mathrm{H}$, et al. Alpha-synuclein-immunoreactive cortical Lewy bodies are associated with cognitive impairment in Parkinson's disease. Acta Neuropathol 2000;100:285-90.

88 Harding AJ, Halliday GM. Cortical Lewy body pathology in the diagnosis of dementia. Acta Neuropathol 2001;102:355-63.

89 Apayadin H, Ahlskog JE, Parisi JE, et al. Parkinson disease neuropathology: later-developing dementia and loss of the levodopa response. Arch Neurol 2002;59:102-12.

90 Mattila PM, Röyttä M, Torikka H, et al. Cortical Lewy bodies and Alzheimer-type changes in patients with Parkinson's disease. Acta Neuropathol 1998;95:576-82.

91 Kotzbauer PT, Trojanowski JQ, Lee VM. Lewy body pathology in Alzheimer's disease. J Mol Neurosci 2001;17:225-32.

92 Jellinger KA, Seppi K, Wenning GK, et al. Impact of coexistent Alzheimer pathology on the natural history of Parkinson's disease. J Neural Transm 2002;109:329-33.

93 Pletnikova 0 , West $\mathrm{N}$, Lee MK, et al. Abeta deposition is associated with enhanced cortical alpha-synuclein lesions in Lewy body diseases. Neurobiol Aging 2005:26:1183-92.

94 Halliday G, Hely M, Reid W, et al. The progression of pathology in longitudinally followed patients with Parkinson's disease. Acta Neuropathol 2008:115:409-15.

95 Lashley T, Holton JL, Gray E, et al. Cortical $\alpha$-synuclein load is associated with amyloid- $\beta$ plaque burden in a subset of Parkinson's disease patients. Acta Neuropathol 2008;115:417-25.

96 Braak H, Braak E. Cortical and subcortical argyrophilic grains characterize a disease associated with adult onset dementia. Neuropathol App/ Neurobiol 1989;15:13-26.

97 Thal DR, Schultz C, Botez G, et al. The impact of argyrophilic grain disease on the development of dementia and its relationship to concurrent Alzheimer's disease-related pathology. Neuropathol App/ Neurobiol 2005;31:270-79.

98 Sabbagh MN, Sandhu SS, Farlow MR, et al. Correlation of argyrophilic grains at autopsy. Alzheimer Dis Assoc Disord 2009:23:229-33.

99 Perl DP, Olanow CW, Calne D. Alzheimer's disease and Parkinson's disease: distinct entities or extremes of a spectrum of neurodegeneration? Ann Neurol 1998;44:S19-31.

100 Ishizawa T, Mattila P, Davies P, et al. Colocalization of tau and alpha-synuclein epitopes in Lewy bodies. J Neuropathol Exp Neurol 2003;62:389-97.

101 Lee VM, Giasson BI, Trojanowski JQ. More than just two peas in a pod: common amyloidogenic properties of tau and alpha-synuclein in neurodegenerative diseases. Trends Neurosci 2004;27:129-34.

102 Geddes JW. $\alpha$-Synuclein: a potent inducer of tau pathology. Exp Neurol 2005;58:186-90.

103 Alves G, Bronnick K, Aarsland D, et al. CSF amyloid- $\beta$ and tau proteins, and cognitive performance, in early and untreated Parkinson's disease: the Norwegian ParkWest study. J Neurol Neurosurg Psychiatry 2010;81:1080-6.

104 Clinton LK, Blurton-Jones M, Myczek K, et al. Synergistic interactions between Abeta, tau, and alpha-synuclein: acceleration of neuropathology and cognitive decline. J Neurosci 2010;30:7281-9.

105 Montine TJ, Shi M, Quinn JF, et al. CSF Abeta(42) and tau in Parkinson's disease with cognitive impairment. Mov Disord 2010;25:2682-5.

106 Wills J, Jones J, Haggerty T, et al. Elevated tauopathy and alpha synuclein pathology in postmortem Parkinson's disease brains with and without dementia. Exp Neurol 2010;225:210-18

107 O'Brien JT, Erkinjuntti T, Reisberg B, et al. Vascular cognitive impairment. Lancet Neurol 2003;2:89-98.

108 Jellinger K, Attems J. Prevalence and impact of vascular and Alzheimer pathologies in Lewy body disease. Acta Neuropathol 2008;115:427-36. 
109 Kovacs GG, Alafuzoff I, Al-Sarraj S, et al. Mixed brain pathologies in dementia: the BrainNet Europe Consortium experience. Dement Geriatr Cogn Disord 2008:26:343-35.

110 Evans AH, Strafella AP, Weintraub D, et al. Impulsive and compulsive behaviors in Parkinson's disease. Mov Dis 2009;24:1561-79.

111 Torta DM, Castelli L, Zibetti M, et al. On the role of dopamine replacement therapy in decision-making, working memory, and reward in Parkinson disease: does therapy-dose matter? Brain Cogn 2009;71:84-91.

112 Miah IP, Olde Dubbelink KT, Stoffers D, et al. Early-stage cognitive impairment in Parkinson's disease and the influence of dopamine replacement therapy. Eur J Neurol 2012;19:510-16.

113 Gelb DJ, Oliver E, Gilman S. Diagnostic criteria for Parkinson's disease. Arch Neurol 1999;56:33-9.

114 Braak H, Alafuzoff I, Arzberger T, et al. Staging of Alzheimer disease-associated neurofibrillary pathology using paraffin sections and immunocytochemistry. Acta Neuropathol 2006;112:389-404.

115 Thal DR, Rüb U, Orantes $M$, et al. Phases of A $\beta$-deposition in the human brain and its relevance for the development of AD. Neurology 2002;58:1791-800.

116 The National Institute on Aging. Consensus recommendations for the post-mortem diagnosis of Alzheimer's disease. The National Institute on Aging, and Reagan Institute Working Group on Diagnostic Criteria for the Neuropathological Assessment of Alzheimer's Disease. Neurobiol Aging 1997;18:S1-2.

117 Yeh P, Walters AS, Tsuang JW. Restless legs syndrome: a comprehensive overview on its epidemiology, risk factors and treatment. Sleep Breath 2011;0ct 26 (Epub ahead of print) PMID: 22038683.

118 Grudzien A, Shaw P, Weintraub S, et al. Locus coeruleus neurofibrillary degeneration in aging, mild cognitive impairment and early Alzheimer's disease. Neurobiol Aging 2007;28:327-35

119 Rye DB. Contributions of the pedunculopontine region to normal and altered REM sleep. Sleep 1997;20:757-88.

120 Saper CB, Chou TC, Scammell TE. The sleep switch: hypothalamic control of sleep and wakefulness. Trends Neurosci 2001:24:726-31.

121 Boeve BF, Silber MH, Saper CB, et al. Pathophysiology of REM sleep behaviour disorder and relevance to neurodegenerative disease. Brain 2007;130:2270-88.

122 Arnulf I, Leu-Semenescu S. Sleepiness in Parkinson's disease. Parkinsonism Relat Disord 2009; (Suppl 3):S101-4.

123 Arnulf I, Leu S, Oudiette D. Abnormal sleep and sleepiness in Parkinson's disease. Curr Opin Neurol 2008;21:472-7.

124 Boeve BF, Dickson DW, Olson EJ, et al. Insights into REM sleep behavior disorder pathophysiology in brainstem-predominant Lewy body disease. Sleep Med 2007:8:60-4.

125 Fuller PM, Saper CB, Lu J. The pontine REM switch: past and present. J Physiol 2007:584:735-41.

126 Schenck CH, Bundlie SR, Mahowald MW. Delayed emergence of a parkinsonian disorder in $38 \%$ of 29 older men initially diagnosed with idiopathic rapid eye movement sleep behavior disorder. Neurology 1996;46:388-93.

127 Olson EJ, Boeve BF, Silber MH. Rapid eye movement sleep behavior disorder: demographic, clinical and laboratory findings in 93 cases. Brain 2000;123:331-9.

128 Stiasny-Kolster K, Mayer G, Schäfer S, et al. The REM sleep behavior disorder screening questionnaire - a new diagnostic instrument. Mov Disord 2007;22:2386-93.

129 Vendette M, Gagnon JF, Décary A, et al. REM sleep behavior disorder predicts cognitive impairment in Parkinson disease without dementia. Neurology 2007:69:1843-9.

130 Postuma RB, Gagnon JF, Vendette M, et al. Quantifying the risk of neurodegenerative disease in idiopathic REM sleep behavior disorder. Neurology 2009;72:1296-300

131 Postuma RB, Gagnon JF, Rompré S, et al. Severity of REM atonia loss in idiopathic REM sleep behavior disorder predicts Parkinson disease. Neurology 2010;19:239-44.

132 Weintraub D, Doshi J, Koka D, et al. Neurodegeneration across stages of cognitive decline in Parkinson disease. Arch Neurol 2011;68:1562-8.

133 Weintraub D, Dietz N, Duda JE, et al. Alzheimer's disease pattern of brain atrophy predicts cognitive decline in Parkinson's disease. Brain 2012;135:170-80.

134 Postuma RB, Lang AE, Gagnon JF, et al. How does Parkinsonism start? Prodromal Parkinsonism motor changes in idiopathic REM sleep behavior disorder. Brain 2012;135:1860-70.

135 Ondo WG, dat Vuong K, Khan H, et al. Daytime sleepiness and other sleep disorders in Parkinson's disease. Neurology 2001;57:1392-6.

136 Jankovic J, Wooten M, van der Linden C, et al. Low body weight in Parkinson's disease. South Med J 1992;85:351-4.

137 Bliwise DL, Watts RL, Watts N, et al. Disruptive nocturnal behaviour in Parkinson's disease and Alzheimer's disease. J Geriatr Psychiatry Neurol 1995;8:107-10.

138 Becker RF, Grunt JA. The cervical sympathetic ganglia. Anat Rec 1957;127:1-14.

139 Wrete M. The anatomy of the sympathetic trunk in man. J Anat 1959;93: $448-59$.
140 Pather N, Partab P, Singh B, et al. Cervico-thoracic ganglion: its clinical implications. Clin Anat 2006;19:323-6.

141 Mitchell GA. The autonomic nerve supply of the throat, nose and ear. I Laryngol Otol 1954;68:495-516

142 Rossoni $\mathrm{RB}$, Machado $\mathrm{AB}$, Machado $\mathrm{CR}$, et al. A histochemical study of catecholamines and cholinesterases in the autonomic nerves of the human minor salivary glands. Histochem 1979;11:661-8.

143 Parkinson D. Further observations on the sympathetic pathways to the pupil. Anat Rec 1988:220:108-9.

144 Ito J, Oyagi S, Honjo I. Autonomic innervations in the middle ear and pharynx. Acta Otolaryngol Supp/ 1993;506:90-3

145 Furlan JC. Sympathetic fiber origin of the superior laryngeal nerve and its branches: an anatomical study. Clin Anat 2002;15:271-5.

146 Proctor GB, Carpenter GH. Regulation of salivary gland function by autonomic nerves. Auton Neurosci: Basic and Clinical 2007;133:3-18.

147 Beach TG, Adler $\mathrm{CH}$, Sue LI, et al. Multi-organ distribution of phospohorylated $\alpha$-synuclein histopathology in subjects with Lewy body disorders. Acta Neuropathol 2010;119:689-702.

148 Bateson MC, Gibberd FB, Wilson RSE. Salivary symptoms in Parkinson's disease. Arch Neurol 1973;29:274-5.

149 Edwards LL, Quigley EM, Harned RK, et al. Characterization of swallowing and defecation in Parkinson's disease. Am J Gastroenterol 1994;1:15-25.

150 Hartelius L, Svensson P. Speech and swallowing symptoms associated with Parkinson's disease and multiple sclerosis: a survey. Folia Phoniatr Logop 1994:46:9-17.

151 Miyamoto T, Miyamoto M, Inoue Y, et al. Reduced cardiac 123'-MIBG scintigraphy in idiopathic REM sleep behavior disorder. Neurology 2006;67:2236-8.

152 Tumilasci OR, Cersósimo MG, Belforte JE, et al. Quantitative study of salivary secretion in Parkinson's disease. Mov Disord 2006;21:660-7.

153 Cersósimo MG, Tumilasci OR, Raina GB, et al. Hyposialorrhea as an early manifestation of Parkinson disease. Auton Neurosci 2009;150:150-1.

154 Meyer TK. The larynx for neurologists. Neurologist 2009;215:313-18.

155 Michou E, Hamdy S. Dysphagia in Parkinson's disease: a therapeutic challenge? Exp Rev Neurother 2010:10:875-8.

156 Postuma RB, Lanfranchi PA, Blais $\mathrm{H}$, et al. Cardiac autonomic dysfunction in idiopathic REM sleep behavior disorder. Mov Disord 2010;14:2304-10.

157 Postuma RB, Montplaisir J, Lanfranchi P, et al. Cardiac autonomic denervation in Parkinson's disease is linked to REM sleep behavior disorder. Mov Disord 2011;26:1529-33.

158 Sung HK, Kim JS, Lee KS, et al. The presence and patterns of pharygoesophageal dysmotility in patients with early stage Parkinson disease. Mov Disord 2010;25:2361-8.

159 Valappil RA, Black JE, Broderick MJ, et al. Exploring the electrocardiogram as a potential tool to screen for premotor Parkinson's disease. Mov Disord 2010:25:2296-303.

160 Sauvageot NM, Vaillant M, Diederich NJ. Reduced sympathetically driven heart rate variability during sleep in Parkinson's disease: a case-control polysomnography-based study. Mov Disord 2011;26:234-40.

161 Del Tredici K, Duda JE. Peripheral Lewy body pathology in Parkinson's disease and incidental Lewy body disease: four cases. J Neurol Sci 2011;310:100-6.

162 Nieuwenhuys R. Structure and organisation of fibre systems. In: Nieuwenhuys R, Ten Donkelaar HJ, Nicholson C, et al. eds. The central nervous system of vertebrates. vol 1, Berlin: Springer, 1999:113-57.

163 Iadecola C. Neurovascular regulation in the normal brain and in Alzheimer's disease. Nat Rev Neurosci 2004;5:357-60.

164 Kamagata K, Motoi Y, Hori M, et al. Posterior hypoperfusion in Parkinson's disease with and without dementia measured with arterial spin labeling MRI. J Magn Reson Imaging 2011;33:803-7.

165 Fernández-Seara MA, Mengual E, Vidorreta M, et al. Cortical hypoperfusion in Parkinson's disease assessed using arterial spin labeled perfusion MRI. Neuroimage 2012;59:2743-50.

166 Hattori T, Orimo S, Aoki S, et al. Cognitive status correlate with white matter alteration in Parkinson's disease. Hum Brain Mapp 2012:33:727-39.

167 Hunter JM, Kwan J, Malek-Ahmadi M, et al. Morphological and pathological evolution of the brain microcirculation in aging and Alzheimer's disease. PLOS ONE 2012;7:e36893.

168 Dubois B, Pillon B. Cognitive deficits in Parkinson's disease. J Neurol $1997 ; 244: 2-8$

169 Marien MR, Colpaert FC, Rosenquist AC. Noradrenergic mechanisms in neurodegenerative diseases: a theory. Brain Res Rev 2004;45:38-78.

170 Rommelfanger KS, Weinshenker D. Norepinephrine: the redheaded stepchild of Parkinson's disease. Biochem Pharmacol 2007:74:177-90.

171 Dickson DW, Fujishiro H, Orr C, et al. Neuropathology of non-motor features of Parkinson's disease. Parkinsonism Rel Disord 2009;15(Suppl 3):S1-5.

172 Sonnen JA, Postupna N, Larson EB, et al. Pathologic correlates of dementia in individuals with Lewy body disease. Brain Pathol 2010:20:654-9. 